\title{
FIRST EVIDENCE ON DIFFERENCES IN MAJOR CHARACTERISTICS OF SUCCESSFULLY CROWDFUNDED EUROPEAN PROJECTS VIA STARTNEXT AND KICKSTARTER PLATFORMS
}

\author{
Michał Gałkiewicz ${ }^{162}$
}

https://doi.org/10.31410/itema.2018.390

\begin{abstract}
This study provides an overview of major characteristics of over 14,000 European projects successfully funded by crowds on the platforms Startnext and Kickstarter. Results suggest that the number of crowd supporters and in direct consequence funding significantly differ for most project categories when comparing these donation and reward based platforms. In particular, projects from the categories food, journalism, music and video projects differ significantly in every dimension. Design, games and technology related projects launched on Startnext and Kickstarter have a comparable funding goal, but reach in significantly shorter campaign duration significantly higher number of supporters on Kickstarter. Comics and photography projects showed similar funding goals and funding amounts, while project founders in the categories art and theater reach higher funding on Startnext. Overall, the comparison of successfully funded European projects from two important platforms reveals relevant differences, thus, understanding them is key for regionally and internationally acting investors, SMEs, founders and their advisors.
\end{abstract}

Keywords: Crowdfunding, crowdsourcing, Startnext, Kickstarter, success

\section{Introduction}

The provision of financing for ideas and entrepreneurial projects is often the biggest challenge for individuals, startups and small and medium-sized enterprises (SMEs). Crowdfunding offers a new financing solution in which a group of investors - the crowd - provides project financing by giving small amounts of money. Founders of European projects, however, often do not know which platform to choose for their projects to succeed.

The goal of this study is to analyze and compare key characteristics of successfully crowdfunded European projects from Startnext and Kickstarter platforms. In particular, the aim of this research is to describe the size of projects' funding goals and numbers of crowd supporters in different industries spanning from arts to technology. On Startnext and Kickstarter platforms which are considered to be general, i.e. unspecialized. Finally, the comparison of project properties based on large samples of successfully funded projects might reveal relevant differences between these important platforms - the world's biggest crowdfunding platform Kickstarter and Startnext - the largest crowdfunding platform in Germany/Austria.

For the purposes of this study, a sample of 17,293 successfully funded European projects (handcollected) is used. In particular, the information on the following variables is collected: project category (i.e. Art, Technology etc.), initial funding goal (almost all successful projects obtain at least a funding as high as the funding goal, however, seldom they only reach a pre-specified

${ }^{162}$ University of Szczecin, ul. Mickiewicza 7, 71-101 Szczecin, Poland 
lower funding threshold), funding period start and end (funding period length for money collection), number of backers and comments.

The results of this study provide guidance for founders on which platform to choose for their projects to reach the right crowds. In contrast, funders can also decide where to invest their money in order to be part of the most successful projects. In fact, Kickstarter and Startnext act as the most important crowdfunding platforms for European projects, thus, understanding the differences between relevant project characteristics on both is important for investors, SMEs, founders and their advisors.

Overall, this study adds to the growing body of literature on success factors, e.g. Mollick (2014), Koch and Siering (2015), Zvilichovsky at al. (2015), Forbes and Schaefer (2017), and Galkiewicz and Galkiewicz (2018), but addresses the topic with a more general approach by emphasizing the differences between general and industry specific characteristics of European projects crowdfunded on Kickstarter and Startnext platforms using large data samples.

The rest of the paper proceeds as follows. Section 2 presents a brief background on the topic of crowdfunding, while data are presented in section 3. Section 4 shows the results of the analyzes of European projects' key characteristics with the associated implications for project founders. Section 5 concludes the paper.

\section{Background on Crowdfunding and Related Literature}

In general, Agrawal et al. 2014 argues that compared to other more traditional ways of financing, crowdfunding is a possibility to get funds cheaper. This is due to the fact that founders are able to address a vast public and, therefore, find backers with highest interest in the product/reward/equity. These authors also add that many creators are interested in direct feedback from customers on their products allowing for optimal product development early on. Moreover, founders are enhanced to link their project with their social media accounts which will provide them with feedback from a larger audience. Courtney, Dutta, and Li (2017) support the theory and add that certain signals, such as the quality of the project, decrease the information asymmetry and increase the participation of the crowd.

The basic idea of crowdfunding is not new. This form of financing was already used hundreds of years ago. The first uses of the crowdfunding model can be found in the subscription model of the 17th and 18th centuries. Back then, it was mainly used to finance the production of books. The "reward" for the investors, for example, was that they were named in the book (Dömötör (2015). Only six years later, the first crowdfunding platform was launched under the name ArtistShare for creative artists in the music business which tries to bypass record companies, middlemen and complicated deal structures and connect artists directly with their fans. Even though the basic idea behind crowdfunding is not new, its modern version is a relatively young form of financing since much of its development has happened between 2006 and 2009 . Technological innovations which were the basis for new website architectures such as Web 2.0 technologies laid the foundation for crowdfunding platforms. Increasingly restrictive bank lending, which was caused by the 2007-2009 financial crisis, made borrowers dependent on new forms of funding. Falling interest rates, on the other hand, made investors look for alternative forms of financing offering a potentially higher yield (Delivorias 2017).

There are several types of crowdfunding campaigns that differ in their purpose. Some campaigns raise funds for non-profit, while others collect money for for-profit projects or 
organizations. One of the most commonly used classifications was developed by the consulting agency Massolution. It distinguishes between four categories of campaigns (Crowdexpert, 2016):

- Donation-based: Funders do not receive any reward for their contributions. There might be the chance for funders to be entitled to tax reductions, depending on the project and jurisdiction.

- Reward-based: Funders receive goods or services in exchange for their contributions.

- Lending-based: Funders receive an attractive interest payment in exchange for financing a project.

- Equity-based: Funders receive shares in the financed venture in exchange for their contributions (Delivorias 2017).

At the moment, there are about 2,000 crowdfunding platforms online worldwide. All those platforms have the same motivation, namely to provide contracts, advice and support for the implementation of crowdfunding projects with the help of technology and standardized processes (Galkiewicz and Galkiewicz (2018)). Nevertheless, they are aligned to different topics and categories and differ in their geographical reach. For this study, we used projects from the platforms Kickstarter and Startnext. Kickstarter is operating worldwide with a total pledged amount of $\$ 3,979,750,84,153,091$ successful projects and over 15,400,000 supporters. Startnext is focused on German speaking countries with a total pledged amount of $€ 59,084,179$ over 6,500 successful projects and more then 1,000,000 supporters.

\section{Data and Methodology}

This study focuses on key project characteristics of over 17,293 European projects successfully funded by crowds on the platforms Startnext and Kickstarter in the time between 2013 and 2018. The hand-collected sample from Startnext contains 4,186 records divided into 23 categories, while the dataset from Kickstarter contains 13,107 records belonging to 15 categories. For funding goals and funding amounts of projects from Kickstarter platform are translated into Euro amounts by applying the respective average exchange rate in a year. 
Table 1: Startnext and Kickstarter projects - a general overview of the sample

\begin{tabular}{|c|c|c|c|c|c|c|c|}
\hline & $\mathbf{N}$ & Mean & Median & SD & MIIN & MAX & WRS [Prob $>|z|]$ \\
\hline Startnext & & & & & & & \\
\hline Funding Goal (in $€$ ) & 4186 & 12139 & 5000 & 50234 & 50 & 2000000 & \\
\hline Funding (in $€$ ) & 4186 & 9809 & 5244 & 22168 & 105 & 801250 & \\
\hline Duration (days) & 4186 & 47 & 42 & 21 & 1 & 181 & \\
\hline Backers (No.) & 4186 & 130 & 71 & 232 & 1 & 5504 & \\
\hline Comments (No.) & 4186 & 18 & 8 & 61 & 0 & 2651 & \\
\hline Kickstarter & & & & & & & \\
\hline Funding Goal (in $€$ ) & 13107 & 9121 & 2889 & 21349 & 0 & 744306 & \\
\hline Funding (in $€$ ) & 13107 & 24470 & 4319 & 126117 & 1 & 6619333 & \\
\hline Duration (days) & 13107 & 31 & 30 & 10 & 1 & 82 & \\
\hline Backers (No.) & 13107 & 351 & 75 & 1888 & 1 & 73206 & \\
\hline Comments (No.) & 13107 & 110 & 4 & 1046 & 0 & 80032 & \\
\hline Total & & & & & & & \\
\hline Funding Goal (in $€$ ) & 17293 & 9852 & 3466 & 30949 & 0 & 2000000 & 0.0000 \\
\hline Funding (in $€$ ) & 17293 & 20921 & 4732 & 110515 & 1 & 6619333 & 0.0000 \\
\hline Duration (days) & 17293 & 35 & 30 & 15 & 1 & 181 & 0.0000 \\
\hline Backers (No.) & 17293 & 297 & 73 & 1651 & 1 & 73206 & 0.0003 \\
\hline Comments (No.) & 17293 & 88 & 5 & 912 & 0 & 80032 & 0.0000 \\
\hline
\end{tabular}

For comparison purposes, 14,005 records from the following common 12 categories were used: Art, Comics, Design, Fashion, Food, Games, Journalism, Music, Photography, Technology, Theater and Video. For the following Wilcoxson-rank-sum-test we chose five independent characteristics common for projects stemming from both platforms: funding goal (in $€$ ), funding (in $€$ ), campaign duration (in days), number of backers (supporters) and number of comments. Table 1 shows a general overview of the data. Results from Wilcoxon-rank-sum tests suggest that the number of crowd supporters and in direct consequence funding significantly differ for most project categories when comparing these two donation- and reward-based platforms. In particular, projects seem to significantly differ in terms of funding goals, funding amounts, number of backers, length of campaign duration and amount of comments across the categories.

\section{Results}

Industry Categories without Similarities. In the categories food, journalism, music and video, projects significantly differ regarding every characteristic. In these categories, projects on the Startnext platform have higher (mostly twice as high) funding goals and funding amounts provided (and commented on) by more backers. As shown in Table 2, in these four categories in total 4,729 projects are compared. The smallest number of 329 projects is observable for the journalism category, while the largest number of projects 2,019 is visible for the music category. For the four categories, the funding amount of the median projects lies within the range of $€ 3,341$ to $€ 10,202$ with the lowest (highest) funding equal to $€ 1(€ 474,233)$. 
Table 2: Categories without similarities: food (f), music (m), video (v) and journalism (j)

\begin{tabular}{|c|c|c|c|c|c|c|c|c|c|c|c|c|c|c|c|c|}
\hline & \multicolumn{4}{|c|}{$\mathrm{N}$} & \multicolumn{4}{|c|}{ Mean } & \multicolumn{4}{|c|}{ Median } & \multicolumn{4}{|c|}{ WRS [ Prob $>|z|]$} \\
\hline & $f$ & $m$ & $v$ & $j$ & $f$ & $m$ & $v$ & $j$ & $f$ & $m$ & $v$ & $j$ & $f$ & $m$ & $v$ & $j$ \\
\hline \multicolumn{17}{|l|}{ Startnext } \\
\hline Funding Goal (in $€$ ) & 235 & 688 & 527 & 163 & 18749 & 7131 & 12899 & 7824 & 12000 & 5000 & 6400 & 4800 & & & & \\
\hline Funding (in $€$ ) & 235 & 688 & 527 & 163 & 14548 & 8423 & 11750 & 7754 & 10465 & 5453 & 6710 & 5016 & & & & \\
\hline Duration (days) & 235 & 688 & 527 & 163 & 46 & 51 & 51 & 42 & 42 & 46 & 46 & 38 & & & & \\
\hline Backers (No.) & 235 & 688 & 527 & 163 & 207 & 125 & 146 & 165 & 137 & 85 & 79 & 94 & & & & \\
\hline Comments (No.) & 235 & 688 & 527 & 163 & 20 & 20 & 26 & 15 & 9 & 12 & 13 & 7 & & & & \\
\hline \multicolumn{17}{|l|}{ Kickstarter } \\
\hline Funding Goal (in $€$ ) & 181 & 1331 & 1438 & 166 & 12484 & 4994 & 6736 & 7394 & 6500 & 2200 & 2441 & 2187 & & & & \\
\hline Funding (in $€$ ) & 181 & 1331 & 1438 & 166 & 18594 & 6485 & 8862 & 9673 & 8312 & 2710 & 2851 & 2731 & & & & \\
\hline Duration (days) & 181 & 1331 & 1438 & 166 & 31 & 34 & 31 & 30 & 30 & 30 & 30 & 30 & & & & \\
\hline Backers (No.) & 181 & 1331 & 1438 & 166 & 196 & 109 & 135 & 173 & 100 & 53 & 41 & 53 & & & & \\
\hline Comments (No.) & 181 & 1331 & 1438 & 166 & 16 & 9 & 8 & 5 & 4 & 1 & 1 & 1 & & & & \\
\hline \multicolumn{17}{|l|}{ Total } \\
\hline Funding Goal (in $€$ ) & 416 & 2019 & 1965 & 329 & 16023 & 5722 & 8389 & 7607 & 10000 & 3051 & 3466 & 3000 & 0.0000 & 0.0000 & 0.0000 & 0.0000 \\
\hline Funding (in $€$ ) & 416 & 2019 & 1965 & 329 & 16308 & 7145 & 9636 & 8722 & 10202 & 3760 & 3988 & 3341 & 0.0000 & 0.0000 & 0.0000 & 0.0022 \\
\hline Duration (days) & 416 & 2019 & 1965 & 329 & 39 & 40 & 36 & 36 & 35 & 32 & 30 & 30 & 0.0000 & 0.0000 & 0.0000 & 0.0000 \\
\hline Backers (No.) & 416 & 2019 & 1965 & 329 & 202 & 114 & 138 & 169 & 123 & 70 & 54 & 74 & 0.0003 & 0.0000 & 0.0000 & 0.0280 \\
\hline \multirow[t]{3}{*}{ Comments (No.) } & 416 & 2019 & 1965 & 329 & 18 & 13 & 13 & 10 & 6 & 2 & 1 & 3 & 0.0000 & 0.0000 & 0.0000 & 0.0000 \\
\hline & \multicolumn{4}{|c|}{ SD } & \multicolumn{4}{|c|}{ MIN } & \multicolumn{4}{|c|}{ MAX } & & & & \\
\hline & $f$ & $m$ & $v$ & $j$ & $f$ & $m$ & $v$ & $j$ & $f$ & $m$ & $v$ & $j$ & & & & \\
\hline \multicolumn{13}{|l|}{ Startnext } & & & & \\
\hline Funding Goal (in $€$ ) & 20474 & 10056 & 27946 & 12430 & 750 & 750 & 300 & 100 & 160000 & 200000 & 400000 & 115000 & & & & \\
\hline Funding (in $€$ ) & 15024 & 12447 & 22203 & 13851 & 807 & 1101 & 445 & 151 & 120634 & 186645 & 321226 & 125225 & & & & \\
\hline Duration (days) & 18 & 21 & 23 & 20 & 5 & 7 & 2 & 6 & 135 & 120 & 144 & 105 & & & & \\
\hline Backers (No.) & 198 & 130 & 269 & 206 & 6 & 11 & 5 & 4 & 1205 & 1780 & 3003 & 1159 & & & & \\
\hline Comments (No.) & 48 & 43 & 121 & 23 & 0 & 0 & 0 & 0 & 676 & 843 & 2651 & 168 & & & & \\
\hline \multicolumn{17}{|l|}{ Kickstarter } \\
\hline Funding Goal (in $€$ ) & 21686 & 8913 & 13726 & 16816 & 12 & 1 & 1 & 1 & 231054 & 122029 & 150546 & 150000 & & & & \\
\hline Funding (in $€$ ) & 36722 & 13146 & 24613 & 20728 & 29 & 1 & 1 & 14 & 334607 & 191462 & 474233 & 181800 & & & & \\
\hline Duration (days) & 10 & 12 & 11 & 13 & 1 & 2 & 3 & 5 & 60 & 61 & 74 & 61 & & & & \\
\hline Backers (No.) & 322 & 227 & 647 & 307 & 1 & 1 & 1 & 4 & 2763 & 4124 & 17713 & 1701 & & & & \\
\hline Comments (No.) & 36 & 51 & 59 & 20 & 0 & 0 & 0 & 0 & 300 & 930 & 1433 & 239 & & & & \\
\hline \multicolumn{17}{|l|}{ Total } \\
\hline Funding Goal (in $€$ ) & 21213 & 9371 & 18827 & 14785 & 12 & 1 & 1 & 1 & 231054 & 200000 & 400000 & 150000 & & & & \\
\hline Funding (in $€$ ) & 26762 & 12942 & 24019 & 17658 & 29 & 1 & 1 & 14 & 334607 & 191462 & 474233 & 181800 & & & & \\
\hline Duration (days) & 17 & 18 & 18 & 17 & 1 & 2 & 2 & 5 & 135 & 120 & 144 & 105 & & & & \\
\hline Backers (No.) & 259 & 200 & 570 & 262 & 1 & 1 & 1 & 4 & 2763 & 4124 & 17713 & 1701 & & & & \\
\hline Comments (No.) & 43 & 49 & 81 & 22 & 0 & 0 & 0 & 0 & 676 & 930 & 2651 & 239 & & & & \\
\hline
\end{tabular}

Industry Categories with Similarities. For the categories comics and photography, projects show similar funding goals and funding amounts. However, these launched on Kickstarter reach in significantly shorter campaign duration a significantly higher number of supporters (in mean and median). As shown in Table 3, in the categories comics and photography, in total 1,176 project are compared. The photography category is the smaller one with 547 projects, while the comics category contains 629 projects. The funding amount of median projects lies within the range of $€ 2,685$ to $€ 3,456$ with the lowest (highest) funding equal to $€ 15$ ( $€ 836,937$ ). 
Table 3: Project characteristics in the categories photography (p) and comics (c)

\begin{tabular}{|c|c|c|c|c|c|c|c|c|c|c|c|c|c|c|}
\hline & \multicolumn{2}{|l|}{$\mathbf{N}$} & \multicolumn{2}{|c|}{ Mean } & \multicolumn{2}{|c|}{ Median } & \multicolumn{2}{|c|}{ SD } & \multicolumn{2}{|c|}{ MIN } & \multicolumn{2}{|c|}{ MAX } & \multicolumn{2}{|c|}{$\mid$ WRS [Prob $>|z|]$} \\
\hline & $p$ & $c$ & $p$ & $c$ & $p$ & $c$ & $p$ & $c$ & $p$ & $c$ & $p$ & $c$ & $p$ & $c$ \\
\hline Startnext & & & & & & & & & & & & & & \\
\hline Funding Goal (in $€$ ) & 139 & 41 & 5174 & 3556 & 3000 & 2000 & 9260 & 4700 & 100 & 350 & 100000 & 22777 & & \\
\hline Funding (in $€$ ) & 139 & 41 & 5625 & 4797 & 3180 & 2140 & 11164 & 9555 & 230 & 653 & 122714 & 59623 & & \\
\hline Duration (days) & 139 & 41 & 48 & 45 & 41 & 34 & 24 & 24 & 10 & 16 & 160 & 92 & & \\
\hline Backers (No.) & 139 & 41 & 76 & 91 & 47 & 54 & 98 & 143 & 4 & 13 & 603 & 897 & & \\
\hline Comments (No.) & 139 & 41 & 11 & 9 & 7 & 7 & 14 & 7 & 0 & 0 & 83 & 22 & & \\
\hline \multicolumn{15}{|l|}{ Kickstarter } \\
\hline Funding Goal (in $€$ ) & 408 & 588 & 6924 & 4240 & 2755 & 1469 & 9979 & 12522 & 1 & 12 & 96440 & 244057 & & \\
\hline Funding (in $€$ ) & 408 & 588 & 13162 & 8304 & 3667 & 2784 & 51980 & 38308 & 15 & 97 & 656903 & 836937 & & \\
\hline Duration (days) & 408 & 588 & 32 & 30 & 30 & 30 & 12 & 9 & 2 & 2 & 82 & 60 & & \\
\hline Backers (No.) & 408 & 588 & 150 & 178 & 62 & 100 & 381 & 312 & 1 & 5 & 4791 & 3737 & & \\
\hline Comments (No.) & 408 & 588 & 8 & 56 & 2 & 6 & 23 & 915 & 0 & 0 & 256 & 22164 & & \\
\hline \multicolumn{15}{|l|}{ Total } \\
\hline Funding Goal (in $€$ ) & 547 & 629 & 6480 & 4196 & 2888 & 1500 & 9823 & 12165 & 1 & 12 & 100000 & 244057 & 0.9087 & 0.1876 \\
\hline Funding (in $€$ ) & 547 & 629 & 11247 & 8075 & 3456 & 2685 & 45347 & 37125 & 15 & 97 & 656903 & 836937 & 0.2275 & 0.4209 \\
\hline Duration (days) & 547 & 629 & 36 & 31 & 30 & 30 & 17 & 11 & 2 & 2 & 160 & 92 & 0.0000 & 0.0004 \\
\hline Backers (No.) & 547 & 629 & 132 & 173 & 56 & 94 & 335 & 305 & 1 & 5 & 4791 & 3737 & 0.0061 & 0.0002 \\
\hline Comments (No.) & 547 & 629 & 9 & 53 & 3 & 6 & 21 & 885 & 0 & 0 & 256 & 22164 & 0.0000 & 0.8060 \\
\hline
\end{tabular}

Even though fashion projects have significantly higher funding goals on Startnext, similar funding amounts are significantly faster collected on Kickstarter from a comparable group of backers. Further as shown in Table 4, this category contains 1,017 projects. The funding amount of the median project equals to $€ 7,210$ with the lowest (highest) funding equal to $€ 20$ $(€ 382,998)$.

Table 4: Fashion category project characteristics

\begin{tabular}{|c|c|c|c|c|c|c|c|}
\hline & $\mathbf{N}$ & Mean & Median & SD & MIN & MAX & $\mid$ WRS [Prob $>|\mathbf{z}|]$ \\
\hline Startnext & & & & & & & \\
\hline Funding Goal (in $€$ ) & 128 & 10341 & 6000 & 11758 & 400 & 70000 & \\
\hline Funding (in $€$ ) & 128 & 9440 & 5961 & 11401 & 411 & 73819 & \\
\hline Duration (days) & 128 & 43 & 39 & 17 & 10 & 90 & \\
\hline Backers (No.) & 128 & 102 & 68 & 115 & 5 & 876 & \\
\hline Comments (No.) & 128 & 22 & 11 & 44 & 0 & 402 & \\
\hline \multicolumn{8}{|l|}{ Kickstarter } \\
\hline Funding Goal (in $€$ ) & 889 & 8702 & 5000 & 11069 & 6 & 100000 & \\
\hline Funding (in $€$ ) & 889 & 17820 & 7415 & 36859 & 20 & 382998 & \\
\hline Duration (days) & 889 & 31 & 30 & 9 & 3 & 63 & \\
\hline Backers (No.) & 889 & 174 & 69 & 483 & 1 & 9086 & \\
\hline Comments (No.) & 889 & 33 & 4 & 106 & 0 & 1372 & \\
\hline \multicolumn{8}{|l|}{ Total } \\
\hline Funding Goal (in $€$ ) & 1017 & 8908 & 5000 & 11166 & 6 & 100000 & 0.0053 \\
\hline Funding (in $€$ ) & 1017 & 16766 & 7210 & 34806 & 20 & 382998 & 0.5254 \\
\hline Duration (days) & 1017 & 33 & 30 & 11 & 3 & 90 & 0.0000 \\
\hline Backers (No.) & 1017 & 165 & 69 & 454 & 1 & 9086 & 0.5525 \\
\hline Comments (No.) & 1017 & 32 & 5 & 100 & 0 & 1372 & 0.0003 \\
\hline
\end{tabular}

Industry Categories with Some Similarities and Differences. For the categories design, games and technology, projects launched on Startnext and Kickstarter have a comparable funding goal, but reach in significantly shorter campaign duration a significantly higher number of supporters on Kickstarter. This automatically translates into significantly higher funding amounts on Kickstarter. Additionally, the significantly higher number of comments for Kickstarter projects reveals higher interest of the Kickstarter crowd for this type of projects. As shown in Table 5, in these three categories in total 4,613 project are compared. The technology 
category contains 1,206 projects, design 1,522 and games 1,885 projects. The funding amount of median projects lies within the range of $€ 10,487$ to $€ 21,003$ with the lowest (highest) funding equal to $€ 2(€ 6,619,333)$.

Table 5: Categories with some similarities: design (d), games (g) and technology ( $\mathrm{t}$ )

\begin{tabular}{|c|c|c|c|c|c|c|c|c|c|c|c|c|}
\hline & \multicolumn{3}{|c|}{$\mathbf{N}$} & \multicolumn{3}{|c|}{ Mean } & \multicolumn{3}{|c|}{ Median } & \multicolumn{3}{|c|}{ WRS [ Prob $>|z|]$} \\
\hline & $d$ & $g$ & $t$ & $d$ & $g$ & $t$ & $d$ & $g$ & $t$ & $d$ & $g$ & $t$ \\
\hline Startnext & & & & & & & & & & & & \\
\hline Funding Goal (in $€$ ) & 101 & 65 & 45 & 10007 & 6618 & 29096 & 4500 & 5000 & 10000 & & & \\
\hline Funding (in $€$ ) & 101 & 65 & 45 & 12879 & 8678 & 21296 & 4881 & 6084 & 9502 & & & \\
\hline Duration (days) & 101 & 65 & 45 & 43 & 48 & 61 & 38 & 42 & 56 & & & \\
\hline Backers (No.) & 101 & 65 & 45 & 192 & 169 & 113 & 84 & 110 & 61 & & & \\
\hline Comments (No.) & 101 & 65 & 45 & 22 & 55 & 71 & 12 & 28 & 19 & & & \\
\hline \multicolumn{13}{|l|}{ Kickstarter } \\
\hline Funding Goal (in $€$ ) & 1421 & 1820 & 1161 & 14585 & 11878 & 24988 & 6000 & 5000 & 11022 & & & \\
\hline Funding (in $€$ ) & 1421 & 1820 & 1161 & 51943 & 50571 & 66792 & 11871 & 10715 & 22528 & & & \\
\hline Duration (days) & 1421 & 1820 & 1161 & 32 & 29 & 33 & 30 & 30 & 30 & & & \\
\hline Backers (No.) & 1421 & 1820 & 1161 & 416 & 1210 & 552 & 123 & 243 & 198 & & & \\
\hline Comments (No.) & 1421 & 1820 & 1161 & 93 & 515 & 204 & 24 & 88 & 39 & & & \\
\hline \multicolumn{13}{|l|}{ Total } \\
\hline Funding Goal (in $€$ ) & 1522 & 1885 & 1206 & 14282 & 11696 & 25141 & 6000 & 5000 & 11000 & 0.2732 & 0.9487 & 0.8248 \\
\hline Funding (in $€$ ) & 1522 & 1885 & 1206 & 49351 & 49127 & 65094 & 11018 & 10487 & 21003 & 0.0000 & 0.0001 & 0.0036 \\
\hline Duration (days) & 1522 & 1885 & 1206 & 33 & 29 & 34 & 30 & 30 & 30 & 0.0000 & 0.0000 & 0.0000 \\
\hline Backers (No.) & 1522 & 1885 & 1206 & 401 & 1175 & 536 & 116 & 236 & 189 & 0.0001 & 0.0000 & 0.0000 \\
\hline Comments (No.) & 1522 & 1885 & 1206 & 88 & 499 & 199 & 23 & 83 & 37 & 0.0000 & 0.0000 & 0.0188 \\
\hline
\end{tabular}

\begin{tabular}{|c|c|c|c|c|c|c|c|c|c|}
\hline & \multicolumn{3}{|c|}{ SD } & \multicolumn{3}{|c|}{ MIN } & \multicolumn{3}{|c|}{ MAX } \\
\hline & $d$ & $g$ & $t$ & $d$ & $g$ & $t$ & $d$ & $g$ & $t$ \\
\hline \multicolumn{10}{|l|}{ Startnext } \\
\hline Funding Goal (in $€$ ) & 18002 & 5665 & 75984 & 500 & 100 & 250 & 150000 & 26000 & 500000 \\
\hline Funding (in $€$ ) & 26173 & 10245 & 31849 & 500 & 130 & 257 & 190232 & 58150 & 164484 \\
\hline Duration (days) & 19 & 21 & 25 & 9 & 14 & 9 & 92 & 92 & 120 \\
\hline Backers (No.) & 584 & 175 & 154 & 3 & 5 & 5 & 5504 & 880 & 818 \\
\hline Comments (No.) & 26 & 128 & 228 & 0 & 0 & 2 & 121 & 1000 & 1482 \\
\hline \multicolumn{10}{|l|}{ Kickstarter } \\
\hline Funding Goal (in $€$ ) & 29419 & 26094 & 40887 & 1 & 1 & 1 & 463709 & 500000 & 744306 \\
\hline Funding (in $€$ ) & 197756 & 247063 & 158911 & 13 & 3 & 2 & 4809548 & 6619333 & 3217126 \\
\hline Duration (days) & 10 & 9 & 10 & 3 & 1 & 7 & 74 & 60 & 70 \\
\hline Backers (No.) & 1131 & 4703 & 1117 & 1 & 1 & 1 & 18550 & 73206 & 12075 \\
\hline Comments (No.) & 245 & 2642 & 739 & 0 & 0 & 0 & 3674 & 80032 & 13287 \\
\hline \multicolumn{10}{|l|}{ Total } \\
\hline Funding Goal (in $€$ ) & 28820 & 25679 & 42670 & 1 & 1 & 1 & 463709 & 500000 & 744306 \\
\hline Funding (in $€$ ) & 191443 & 242891 & 156273 & 13 & 3 & 2 & 4809548 & 6619333 & 3217126 \\
\hline Duration (days) & 11 & 10 & 12 & 3 & 1 & 7 & 92 & 92 & 120 \\
\hline Backers (No.) & 1104 & 4625 & 1100 & 1 & 1 & 1 & 18550 & 73206 & 12075 \\
\hline Comments (No.) & 237 & 2598 & 726 & 0 & 0 & 0 & 3674 & 80032 & 13287 \\
\hline
\end{tabular}

Remaining Industry Categories. Finally, projects in the categories art and theater rely on a similar number of backers, but projects from Startnext have significantly higher funding goals and funding amounts, (the latter are collected during longer periods). As shown in Table 6, in these two categories in total 2,470 project are compared. The theater category is the smaller one with 793 projects - the art category contains 1,677 projects. The funding amount of median projects lies within the range of $€ 1,863$ to $€ 2,343$ with the lowest (highest) funding equal to $€ 2$ (€442,934). 
Table 6: Projects characteristics in the categories art (a) and theater (t)

\begin{tabular}{|c|c|c|c|c|c|c|c|c|c|c|c|c|c|c|}
\hline & \multicolumn{2}{|l|}{$\mathbf{N}$} & \multicolumn{2}{|c|}{ Mean } & \multicolumn{2}{|c|}{ Median } & \multicolumn{2}{|c|}{ SD } & \multicolumn{2}{|c|}{ MIN } & \multicolumn{2}{|c|}{ MAX } & \multicolumn{2}{|c|}{$\mid$ WRS [Prob $>|z|]$} \\
\hline & $a$ & $t$ & $a$ & $t$ & $a$ & $t$ & $a$ & $t$ & $a$ & $t$ & $a$ & $t$ & $a$ & $t$ \\
\hline Startnext & & & & & & & & & & & & & & \\
\hline Funding Goal (in $€$ ) & 233 & 346 & 5479 & 4138 & 2600 & 2500 & 9167 & 5834 & 200 & 150 & 100000 & 75000 & & \\
\hline Funding (in $€$ ) & 233 & 346 & 4893 & 4428 & 2654 & 2848 & 5869 & 9534 & 205 & 200 & 51726 & 165947 & & \\
\hline Duration (days) & 233 & 346 & 41 & 44 & 36 & 39 & 19 & 20 & 4 & 6 & 92 & 130 & & \\
\hline Backers (No.) & 233 & 346 & 57 & 45 & 33 & 33 & 67 & 57 & 3 & 3 & 528 & 813 & & \\
\hline Comments (No.) & 233 & 346 & 8 & 8 & 4 & 6 & 13 & 9 & 0 & 0 & 128 & 48 & & \\
\hline Kickstarter & & & & & & & & & & & & & & \\
\hline Funding Goal (in $€$ ) & 1444 & 447 & 3483 & 3356 & 1076 & 1733 & 8640 & 14497 & 0 & 1 & 137771 & 300000 & & \\
\hline Funding (in $€$ ) & 1444 & 447 & 6524 & 3823 & 1664 & 1855 & 24554 & 15816 & 2 & 79 & 442934 & 322202 & & \\
\hline Duration (days) & 1444 & 447 & 29 & 31 & 30 & 30 & 11 & 12 & 2 & 7 & 60 & 60 & & \\
\hline Backers (No.) & 1444 & 447 & 104 & 53 & 38 & 31 & 439 & 84 & 1 & 3 & 9665 & 1049 & & \\
\hline Comments (No.) & 1444 & 447 & 9 & 1 & 1 & 0 & 46 & 5 & 0 & 0 & 1062 & 90 & & \\
\hline Total & & & & & & & & & & & & & & \\
\hline Funding Goal (in $€$ ) & 1677 & 793 & 3760 & 3697 & 1240 & 2112 & 8739 & 11547 & 0 & 1 & 137771 & 300000 & 0.0000 & 0.0000 \\
\hline Funding (in $€$ ) & 1677 & 793 & 6298 & 4087 & 1863 & 2343 & 22894 & 13437 & 2 & 79 & 442934 & 322202 & 0.0000 & 0.0000 \\
\hline Duration (days) & 1677 & 793 & 31 & 36 & 30 & 30 & 13 & 17 & 2 & 6 & 92 & 130 & 0.0000 & 0.0000 \\
\hline Backers (No.) & 1677 & 793 & 98 & 50 & 37 & 31 & 408 & 73 & 1 & 3 & 9665 & 1049 & 0.4519 & 0.8273 \\
\hline Comments (No.) & 1677 & 793 & 9 & 4 & 1 & 1 & 43 & 7 & 0 & 0 & 1062 & 90 & 0.0000 & 0.0000 \\
\hline
\end{tabular}

\section{Conclusion}

This study provides a first comprehensive overview of the key project characteristics of over 14,000 European projects successfully funded by crowds on the platforms Startnext and Kickstarter in the time between 2013 and 2018. The aim of this research is to offer general and industry specific information together with clear recommendations for founders on which platform to choose for their projects to succeed by reaching the right funders. Results from Wilcoxon-rank-sum tests suggest that the number of crowd supporters and in direct consequence funding significantly differ for most project categories when comparing these two donation- and reward-based platforms.

In the categories food, journalism, music and video, projects launched on Startnext have almost twice as high funding goals and funding amounts as Kickstaretr's projects. In the categories design, games and technology projects launched on Startnext and Kickstarter have a comparable funding goal, but reach in significantly shorter campaign durations significantly larger crowds on Kickstarter. For the categories comics and photography, projects showed similar funding goals and funding amounts on both platforms. Fashion related projects reach funding amounts similar to Startnext's projects significantly faster on Kickstarter. Projects in the categories art and theater reach on Startnext significantly higher funding goals and funding during longer campaigns. Further research could take more crowdfunding platforms into account which would lead to a more detailed analysis of which platform to choose by founders or/and support by funders.

\section{References}

Agrawal, A., C. Catalini, and A. Goldfarb, 2015, Crowdfunding: Geography, Social Networks, and the Timing of Investment Decisions, Journal of Economics \& Management Strategy 24 (2), p. 253-274.

Courtney, C., Dutta, S., \& Li, Y. (2017). Resolving Information Asymmetry: Signaling, Endorsement, and Crowdfunding Success. Entrepreneurship Theory and Practice, 41(2), 265-290. https://doi.org/10.1111/etap.12267

Delivorias, A., 2017, Crowdfunding in Europe: Introduction and State of Play, available at http://www.europarl.europa.eu/RegData/etudes/BRIE/2017/595882/EPRS_BRI(2017)59 5882 EN.pdf (accessed August 21, 2018). 
Dömötör, F., \& Dömötör, A. (2015). The Power of the Crowd: Crowdinvesting für kapitalsuchende Unternehmen und Investoren [Ebook] (pp. 2-14). Wien: WKO., available at https://www.jungewirtschaft.at/jw/oesterreich/jw_lf_crowdinvesting_3004.pdf. (accessed August 20, 2018).

Forbes, H., and D. Schaefer, 2017, Guidelines for Successful Crowdfunding, Procedia CIRP 60 (2017), p. 398-403.

Gałkiewicz, D. P., and M. Gałkiewicz, 2018, Crowdfunding Monitor 2018: An Overview of European Projects Financed on Startnext and Kickstarter Platforms between 2010 and mid2017, Bermag: Szczecin.

Koch, J., and M. Siering, 2015, Crowdfunding Success Factors: the Characteristics of Successfully Funded Projects on Crowdfunding Platforms, ECIS 2015 Completed Research Papers, Paper 106.

Mollick, E., 2014, The Dynamics of Crowdfunding: An Exploratory Study, Journal of Business Venturing 29 (1), p. 1-16.

Zvilichovsky, D., Y. Inbar, and O. Barzilay, 2015, Playing Both Sides of the Market: Success and Reciprocity on Crowdfunding Platforms, Working Paper.

Crowdexpert, 2016, Crowdfunding Industry Statistics 2015-2016: Massolution Crowdfunding Industry 2015 Report, available at http://crowdexpert.com/crowdfunding-industrystatistics/ (accessed August 21, 2018). 